\title{
LOW BOILING-POINT COMPOUNDS PRODUCED BY PYROLYSIS OF FUNGAL MELANINS AND MODEL PHENOLIC POLYMERS
}

\author{
C. SAIZ-JIMENEZ, F. MARTIN \\ Centro de Edafologia y Biologia Aplicada del Cuarto, \\ Consejo Superior de Investigaciones Cientificas, Apartado 1052, Sevilla, Spain \\ and
}

A. CERT

Instituto Territorial del Servicio Social de Higiene y Seguridad del Trabajo, Apartado 615, Sevilla, Spain

\begin{abstract}
Summary-Pyrolysis-gas chromatography-mass spectrometry was used to characterize fungal melanins and model phenolic polymers. Samples were pyrolysed at $700^{\circ} \mathrm{C}$ for $10 \mathrm{~s}$ and the low boiling-point compounds were separated on a Chromosorb 102 column. Low boiling-point compounds identified with a mass spectrometer coupled to the gas chromatograph were very similar for peptone, a model autoxidative phenolic polymer incorporating peptone, and some fungal melanins. The major low boiling-point components from fungal melanins were related to proteins and to polysaccharides. A nitrogenfree phenolic polymer yielded very small amounts of low boiling-point pyrolysis fragments. The compounds identified appeared to be derived largely from the peptide. carbohydrate, and possibly small amounts of other aliphatic materials in the polymer structures.
\end{abstract}

\section{INTRODUCTION}

Many soil microorganisms, including fungi, actinomycetes, and a lew bacteria synthesize dark polymers. They excrete these into the growth nedia or incorporate them into their cells or spores. The polymers resemble soil humic acids in elementary composition, exchange capacity, resistance to decomposition in soil, i.r. spectra, phenols recovered after Na-amalgam reduction, and in the amino acids released upon hydrolysis with $6 \mathrm{~N} \mathrm{HCl}$ (Martin et al., 1972a).

Schnitzer et al. (1973) suggested on the basis of chemical degradation that three fungal melanins tested were complex materials containing aliphatic and aromatic structures, only some of which were phenolic. Schnitzer and Neyroud (1975) reported that aliphatic structures constituted about $40^{\circ} \%$ of the degradation products of the fungal melanins studied, whereas the remainder consisted of phenolic and benzenecarboxylic acids and dialkyl phthalates. Martin et al. (1974) reported that reductive degradation of fungal melanins yielded between 10 and $60 \%$ ethersoluble substances, and from these $432^{\circ}$ a were phenolic compounds which could be separated by two dimensional t.l.c.

To gain a better understanding of the chemical or gins of humic acids a number of authors l Ladd and Butler, 1966; Martin et al, 1972a) have prepared model humic acid-type polymers from mixtures of phenols and amino acids or proteins. Martin et al. (1972a) indicated how numerous resorcinol and $p$-hydroxycinnamic acid-derived phenols could be polymerized by autoxidative or enzymatic mechanisms and how peptides could be linked into the developing polymers.
The use of pyrolysis-gas chromatography-mass spectrometry, a powerful analytical tool to identify and characterize polymers, should help to clarify the chemical structure of fungal melanins and indicate similarities to other model polymers and soil humic substances. Pyrolysis-gas chromatography-mass spectrometry has apparently not been applied to the characterization of fungal melanins, although whole bacteria and an actinomycete were studied by Simmonds (1970) and Medley et al. (1975).

We have studied the low boiling-point compounds produced by the pyrolysis at $700^{\circ} \mathrm{C}$ of several fungal melanins and model phenolic polymers. At this pyrolysis temperature it is generally recognized that aromatic rings remain virtually intact while considerable breakdown of non-aromalic and substituent groups occur. The low boiling-point volatile products were identified and the results interpreted with respect to possible components of the polymers from which they were derived.

\section{MATERIALS AND METHODS}

The fungi Aspergillus niger, Epicoccum purpurascens, Eurotium echinulatum and Hendersonula toruloidea were used to obtain the melanins. Model polymers were prepared from mixtures of phenols, containing 2,6- and 3,5-dihydroxytoluenes, caffeic, p-hydroxycinnamic, and gallic acids, p-hydroxy, 2,6-dihydroxy, 3,5-dihydroxy, 2,3,4-trihydroxy, and 2,4,6-trihydroxy-benzoic acids, pyrogallol, resorcinol, phloroglucinol, and methylphloroglucinol. This mixture was polymerized autoxidatively at $\mathrm{pH} 8.0$ in the presence or absence of peptone. 
Techniques to cultivate the organisms, to isolate and characterize the melanins, and procedures to synthesize the model polymers have been described by Martin et al. (1967, 1972a, b), Saiz-Jimenez and Marin (1972) and Saiz-Jimenez et al. (1975). The fungal melanins were pyrolysed before and after hydrolysis with $6 \mathrm{~N} \mathrm{HCl}$ to remove peptides and carbohydrates (Riffaldi and Schnitzer, 1973). Carbohydrate contents were determined according to the procedures of Orlov and Sadovnikova (1975).

A CDS Pyroprobe Model 120 pyrolyser was used for the pyrolysis experiments. Samples $(2 \mathrm{mg})$ were introduced directly into the injection port of a PYE Model 104 g.c. and pyrolysed for $10 \mathrm{~s}$ at $700 \mathrm{C}$. The chromatographic effluent was passed via a silicone membrane molecular separator into the mass spectrometer AEI Model MS-30, operated at an ionizing voltage of $70 \mathrm{eV}$ and a resolution of $1000(10 \%$ valley definition). In order to facilitate data acquisition the mass spectrometer was coupled to a DS- 30 computer systent equipped with the appropriate data-handling software. Satisfactory separation of low boiling-point compounds was achieved using a $3 \mathrm{~m} \times 3 \mathrm{~mm}$ stainless steel Chromosorb 102 column operated for $4 \mathrm{~min}$ at $60 \mathrm{C}$, then programmed between 60 and $200^{\circ} \mathrm{C}$ at a rate of $10^{\circ} \mathrm{C} \mathrm{min}$ mind $^{-1}$, and finally operated under isothermal conditions for a period of $20 \mathrm{~min}$ at $200 \mathrm{C}$. The compounds were identified from mass spectra and also by comparing retention times with those of standards using a Hewlett Packard Model $5750 \mathrm{G}$ dual flame-ionization detector under the operating conditions noted above. The presence of two different compounds in the same area did not present a serious problem, because usually their individual spectra could be readily recognised even though they were superimposed. The pyrograms from the gas chromatograph are shown in the figures and are presented in preference to the total ion chromatograms from the mass spectrometer.

\section{RESULTS}

Table 1 lists the pyrolysis products which were identified from the mass spectra of the low boilingpoint fractions. Figure la shows the pyrogram of a

Table 1. Low boling-point compounds identified by pyrolysis of fungal melanins*

$\begin{array}{ll}1 \text { Methane } & 18 \text { Pentene } \\ 2 \text { Ethene } & 19 \text { Pentadiene } \\ 3 \text { Ethane } & 20 \text { Propanenitrile } \\ 4 \text { Methanal } & 21 \text { Acetic acid } \\ 5 \text { Propene } & 22 \text { Methylfuran } \\ 6 \text { Propane } & 23 \text { Pentane } \\ 7 \text { Chloromethane } & 242 \text {-Butanone } \\ 8 \text { Methanol } & 25 \text { Isobutanenitrile } \\ 9 \text { Ethanal } & 26 \text {-Butenal } \\ 10 \text { Methanethiol } & 27 \text { Benzene } \\ 11 \text { Butene-1 } & 28 \text { Dimethylfuran } \\ 12 \text { Butane } & 29 \text { Pyridiue } \\ 13 \text { Butane-2 } & 30 \text { Pyrrol } \\ 14 \text { Acetonitrile } & 31 \text { Unknown } \\ 15 \text { Acrolein } & 32 \text { Toluene } \\ 16 \text { Acetone and Furan } & 33 \text { Furfural } \\ 17 \text { Acrylonitile } & 34 \text { Phenol }\end{array}$

* Numbers refer to peak numbers on pyrograms.

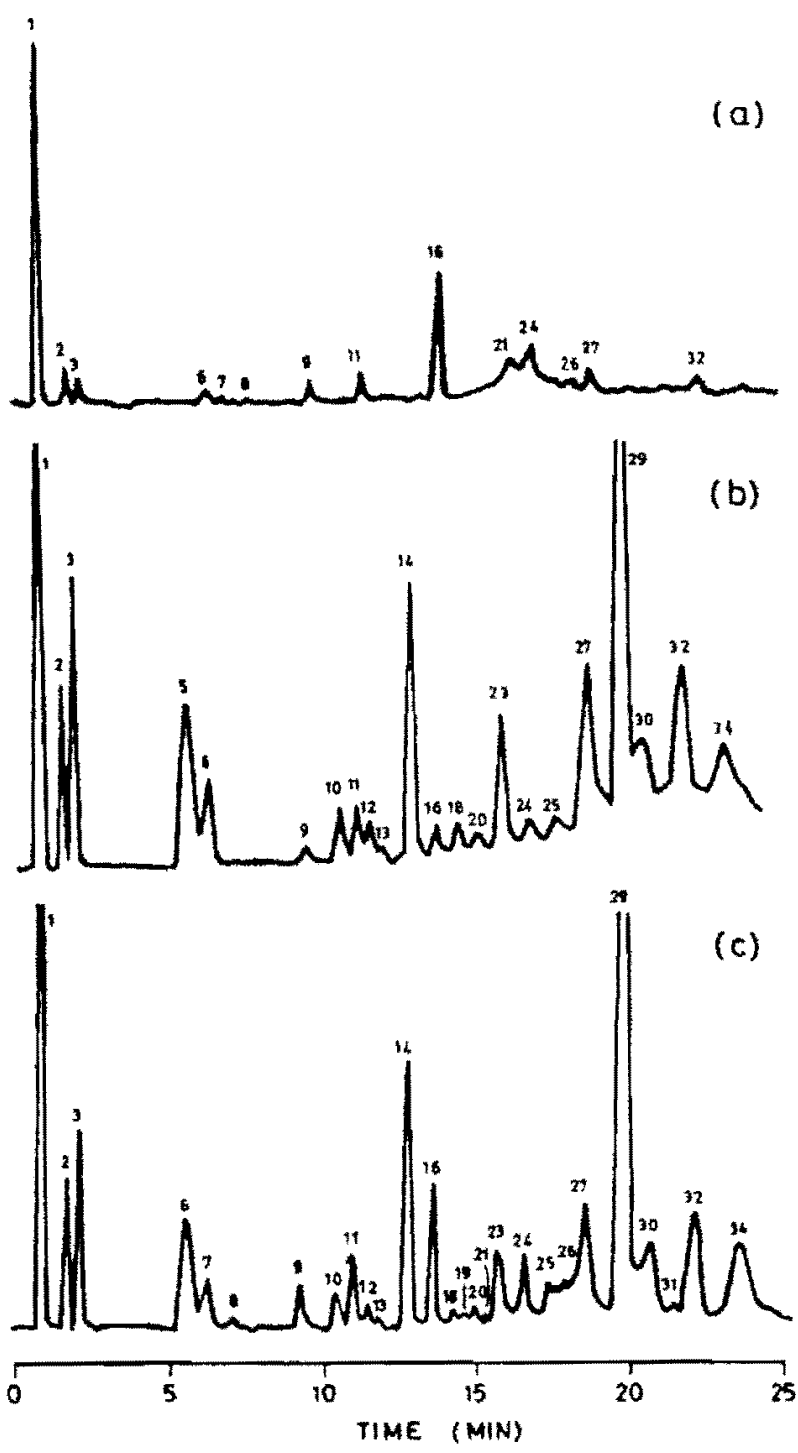

Fig. 1. Pyrograms from: (a) phenolic polymer, (b) popton: (c) phenolic peptone polymer.

polymer formed by autoxidation of a mixture of phenols. By comparing the peak numbers on the pyrogram with the compounds numbers listed in Table 1 it can be seen that the major peaks were from methane and acetone. Minor peaks were from ethene, ethane, propane, ethanal. butene-I, acetic acid. 2-butanone, 2-butenal, benzene and toluene.

From Fig. $1 b$ and Table 1 it will be seen that the major peaks in the peptone pyrogram represented methane, ethene, ethane, propene, acetonitrile, pentanc, benzene, pyridine and toluene. The presence of propane, ethanal, methanethiol, butenes, butane, acetone, propanenitrile, isobutanenitrile, 2-butanone. pyrrol and phenol was also evident. The model autoxidative polymer formed from a mixture of phenols and peptone (Fig. Ic) showed a pyrogram very similar to that for the peptone.

Pyrograms of fungal melanins are shown in Fig. 2. The A. niger melanin (Fig. 2a) shows a number of prominent peaks, especially those for methane, ethene, ethane, propene, ethanal, butane, acetone, furan. methylfuran, pentane, 2-butanone, benzene, dimethylfuran, toluene and furfural. Other important peaks 
were propane, butene-1, acetonitrile, acrolein, propanenitrile, 2-butenal, pyridine, pyrrol, and an unknown compound. Some minor peaks were also present.
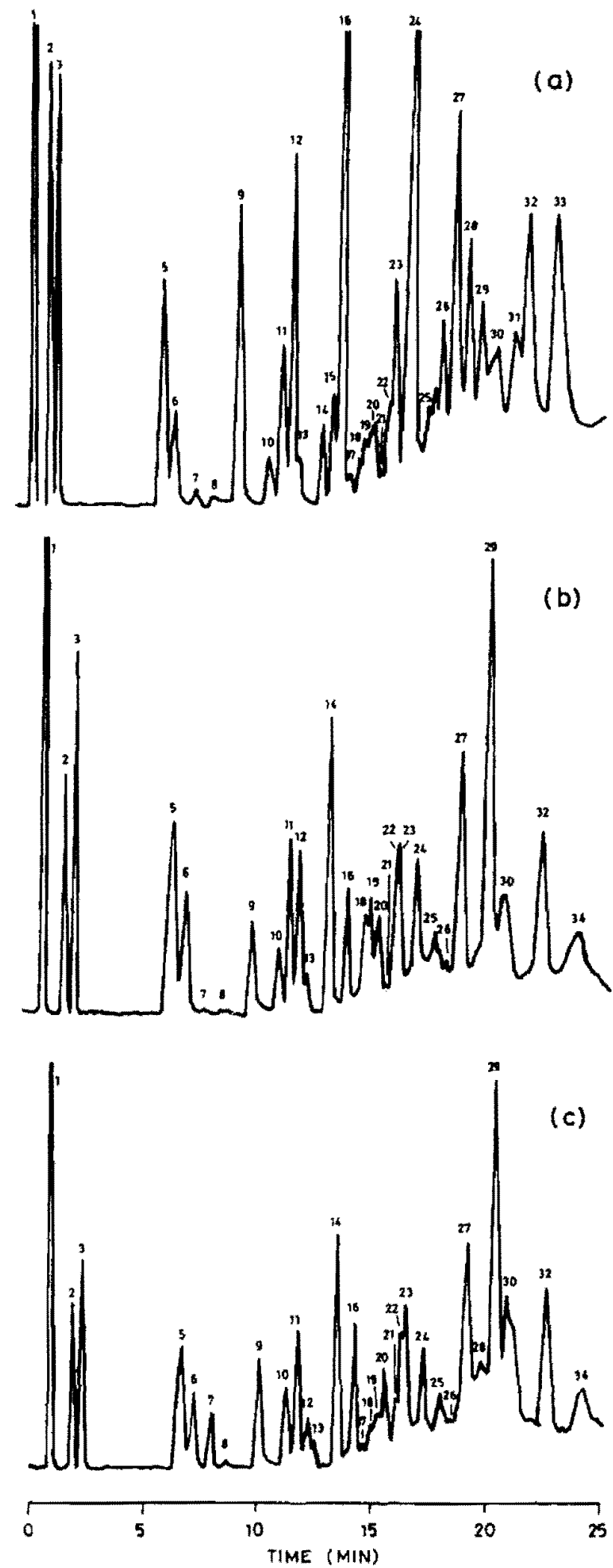

Fig. 2. Pyrograms from fungal melanins. (a) Aspergillus niger, (b) Epicoccum purpurascens. (c) Hendersonula toruloidea.

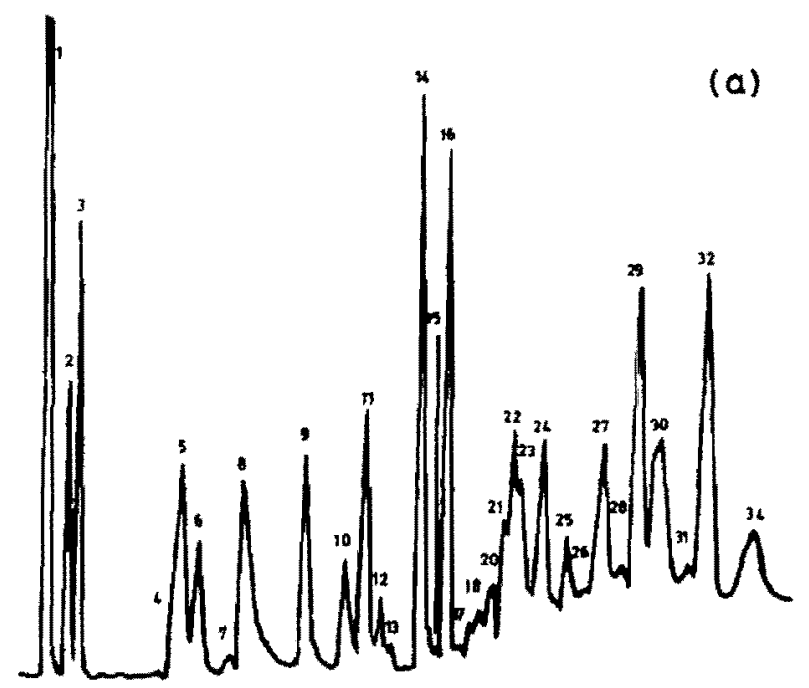

(b)

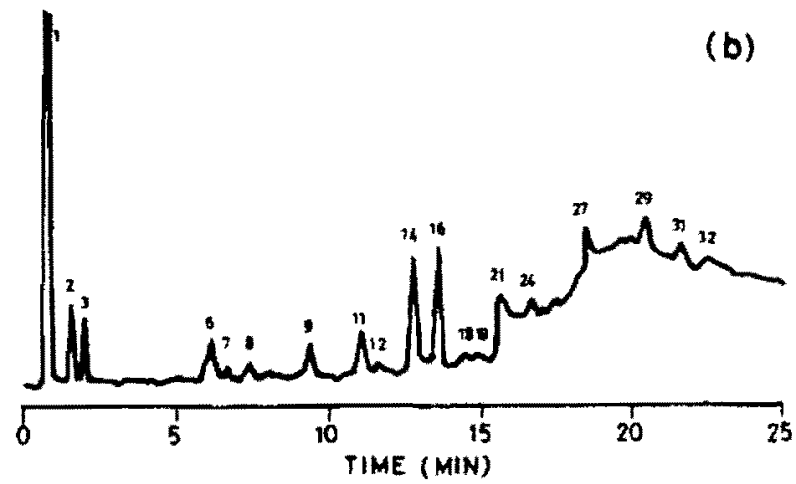

Fig. 3. Pyrograms from Eurotium echinulatum melanin. (a) before acid hydrolysis, (b) after acid hydrolysis.

The pyrograms for the $E$. purpurascens and $H$. toruloidea melanins were very similar (cf. Figs. $2 \mathrm{~b}$ and 2c). Both displayed common major peaks for methane, cthene, ethane, propene, propane, butene-1, acetonitrile, acetone, furan, methylfuran, pentane, 2-butanone, benzene, pyridine, pyrrol and toluene. In addition $E$. purpurascens has butane. The chloromethane peak was much higher for $H$. toruloidea than for $E$. purpurascens melanin, whereas the contrary was true for the pentene and pentadiene peaks.

Figures $3 a$ and $3 b$ present pyrograms for the $E$. echinulatum melanin, before and after hydrolysis with $6 \mathrm{~N} \mathrm{HCl}$, as representative for the fungal melanins. The parent melanin shows major peaks for methane, ethene, ethane, propene, methanol, ethanal, butene-1, acetonitrile, acetone, furan, methylfuran, 2-butanone. benzene, pyridine, pyrrol and toluene. These peaks were drastically reduced or they disappeared in the pyrogram of the hydrolysed sample.

The inorganic gases $\mathrm{CO}, \mathrm{CO}_{2}, \mathrm{H}_{2} \mathrm{O}$ and $\mathrm{NH}_{3}$ were formed as major pyrolysis products from fungal melanins, but these products were not detected with the flame ionization detector and are therefore not included in Table 1.

\section{DISCUSSION}

Based on data of Medley et al. (1975) and our previous work (Martin et al. 1977) the probable origins of the pyrolysis products from the fungal melanins 
can be assigned. When there is equal probability that more than one type of compound contributes to the formation of a fragment, it is listed under all possible sources. Thus, methane, ethene, ethane, propene, propane, butene-1, butane, butene-2, pentene, pentadiene, and pentane are common thermal fragments from proteins, carbohydrates and aliphatic compounds. Methanol, ethanal, acrolein, acetone, furan, acetic acid, methylfuran, 2-butanone, 2-butenal, dimethylfuran and furfural are typical fragments from carbohydrates, though ethanal, acetone and 2-butanone were also identified in proteins. Methanethiol, acetonitrile, acrylonitrile, propanenitrile, isobutanenitrile, benzene, pyridine, pyrrol, toluene and phenol are formed from proteins. Chloromethane possibly originated from secondary reactions between $\mathrm{HCl}$ and methyl groups, but the origin of methanal could not be readily assigned.

Pyrolysis of peptone yielded alkanes, olefins, nitriles, and aromatic and heterocyclic $\mathrm{N}$ compounds. Nitriles, pyrrol and pyridine are of particular interest since they are characteristic fragments. The nitrogenfree autoxidative phenolic polymer produced few and poorly developed peaks, while the phenolic polymer with peptone gave almost the same pyrogram as peptone. This indicated that the protein was the primary source of the low boiling-point fragments. Most of the fragments from the fungal melanins were also characteristic of protein and the pyrograms from the E. purpurase'ens and $H$. toruloidea melanins and those from the phenolic-peptone polymer (cf. Figs 2b, 2c and $1 c)$ were remarkably similar.

$\Lambda$ few of the low boiling-point pyrolysis products from fungal melanins could not have originated from protcinaceous structures. Some of these, especially prominent in the A. niger melanin, were furan derivatives and have been noted upon pyrolysis of plant and soil polysaccharides (Haider et al.. 1977; Martin et al, 1977). This is consistent with the analytical data, which show that this product has a carbohydrate content of $52.5^{\circ}$, and this value is $10-15$ times greater than that for the other fungal melanins. The A. niger melanin was obtained by extraction and acid precipitation (Saiz-Jimenez and Martin, 1972) and it is well-known that this fungus produces high amounts of nigeran, a complex polysaccharide. The carbohydrate content of most fungal melanins range from about 1 to $6^{\circ}$, the $52.5^{\circ}$ value for $A$, niger, therefore, indicates that the preparation was a mixture of melanin and polysaccharide or it is an atypical product.

Alkanes and olefins present in the pyrograms might also arise from aliphatic structures, such as alkanes and fatty acids shown by Schnitzer et al. (1973) and Schnitzer and Neyroud (1975) to be present in fungal humic acid-type polymers. Further studies are in progress to clarify this point.

The $\mathrm{N}$ contents of the melanins studied here ranged from 2.7 to $4.9^{\circ}$, which represents $17-30^{\circ}$, protein in the molecules. Carbohydrates ranged from 4 to $52.5^{\circ}$. Thus, $30-50 \%$ of the melanin structures were composed of acid-hydrolysable products, except for the atypical $A$. niger melanin, which contained $70 \%$. Weight losses would be a little higher because some of the aromatic compounds will also be lost during the procedure. These results agree well with those reported by Schnitzer et al. (1973), who found weight losses ranging from 47 to $82^{\circ}{ }^{\circ}$ after acid hydrolysis of similar melanins. Hydrolysis of the melanins released the protein and polysaccharide components. and the pyrogram of the residue was very similar to that of the protein-free phenolic polymer (cf. Figs 3b and (a). There was, however. evidence for some nitrogeneous compounds in the pyrolysis products of the hydrolysed melanin. Since fungal melanins contain $\mathrm{N}$ which is not hydrolysed to amino acid, it has been postulated that some amino group of proteins are covalently bonded to the benzenoid nucleus to give linkages which resist acid hydrolysis (Ladd and Butler, 1966). Therefore, it seems possible that the N-containing fragments in the pyrogram of the hydrolysed melanin arose from free amino groups in dibasic amino acids or terminal amino acids of the protein chains bonded to the phenolic rings or both.

Our results agree with those of Meuzelaar et al., (1977), who used pyrolysis-mass spectrometry (Curiepoint $510^{\circ} \mathrm{C}$ ) to characterize model phenolic polymers, fungal melanins, and soil humic acids. They found that model oxidative polymers from phenols without addition of peptone yielded fragments at $\mathrm{m} / \mathrm{e}$ $18,28,44,58$ and 60 (probably related to $\mathrm{H}_{2} \mathrm{O}, \mathrm{CO}$. $\mathrm{CO}_{2}$, acetone and acetic acid). Other peaks, except those related to phenols (not studied here), could not be easily detected. The similarities between the spectra of model auloxidative polymer reacted with peptone and those of fungal melanins were especially striking as they contained all the characteristic ion series, and the variability in the relative abundance of the pyrolysis products among the different samples was the same.

According to Haider et al. (1975) and Meuzelaar et at. (1977) fungal melanins are complex phenolicproteinaceous polymers. Saiz-Jimenez and Martin (1978) arrived at the same conclusion from chemical and thermal degradation of the $E$. echimulatum melanin. Melanins are synthesized by fungi by the oxidative coupling of phenolic constituents. The resulting random polymers can incorporate compounds such as protein and certain polysaccharides, especially mixed polymers containing amino acids or amino sugar units with free amino groups, which happen to be available during the polymerization process. As has been demonstrated proteins and to a lesser extent polysaccharides are constituents of melanins and are the source of most of the low boiling-point pyrolysis products.

The pyrograms from fungal melanins and model phenolic polymers incorporating peptone can be compared with those from soil humic acids described by Martin et al. (1977). The different substances show similar spectra but with quantitative differences, according to the protein and carbohydrate contents. Obviously, the similarities between the low boilingpoint pyrograms of fungal melanins and soil humic acids cannot be regarded as conclusive evidence for similarities in the chemical structures of the materials. The low boiling-point compounds identified are derived from protein, carbohydrate and aliphatic groups associated with the polymers. We rccognise the importance of the aromatic fragments for interpretations of similarities between the different polymers and we are proceeding with research in this area. 
Acknowledgements-We thank Professor J. P. Martin, Riverside, and Dr K. Haider, Braunschweig, who provided the phenolic polymers and the E. purpurascens and $H$. tort loidea melanins. For kindly reading and revision of the manuscript we are indebted to Professor M. H. B. Hayes, Birmingham.

\section{REFERENCES}

Haider K., Martin J. P. and Filip Z. (1975) Humus biochemistry. In Soil Biochemistry (E. A. Paul and A. D. Mclaren, Eds). Vol. 4, pp. 195-244. Marcel Dekker. New York.

Haider K. Nagar B. R., Salz C., Meuzelaar H. L. C. and MARTIN J. P. (1977) Studies on soil humic compounds, fungal melanins and model polymers by pyrolysis-mass spectrometry. Soil Organic Motter Studies. Vol. II, pp. 213-220, IAEA, Vienna.

LADD J. H. and Butler J. H. A. (1966) Comparison of some properties of soil humic acids and synthetic phenolic polymers incorporating amino derivatives. Aust. $J$. Soil Res. 4, 41-54.

Martin J. P., Richards S. J. and Haider K. (1967) Properties and decomposition and binding action in soil of humic acid synthesized by Epicoccum nigrum. Soil Sci. Soc. Am. Proc, 31, 657-662.

MARTIN J. P., HaIDER K. and BondietrI E. (1972a) Properties of model humic acids synthesized by phenoloxidase and autoxidation of phenols and other compounds formed by soil fungi. Proc. Int. Meet. Humic Substances, Nieuwersluis, pp. 171-186, Pudoc, Wageningen.

Martin J. P., Hamer K. and WolF D. (1972b) Synthesis of phenols and phenolic polymers by Hendersonula toruloidea in relation to humic acid formation. Soil Sci. Soc. Am. Proc. 36, 577-602.

Martin J. P., Haider K. and Saiz-Jimenez, C, (1974) Sodium amalgam reductive degradation of fungal and model phenolic polymers, soil humic acids, and simple phenolic compounds. Soil Sci. Soc. Am. Proc. 38, 760-765.
Martin F., Salz-Jimenez C. and Cert A. (1977) Pyrolysis-gas chromatography-mass spectrometry of soil humic fractions. 1. The low boiling point compounds. Soil Sci. Soc. Am. J. 41, 114-1118.

Medley E. E., Simmonds P. G. and Manatt S. L. (1975) A pyrolysis-gas chromatography-mass spectrometry study of the actinomycete Streptomyces tongisporoflarus. Biomed. Mass Spectrom. 2, 261-265.

Meuzelaar H. L. C. Haidfr K. NaGaR B. R. and MarTIN J. P. (1977) Comparative studies of pyrolysis-mass spectra of melanins, model phenolic polymers, and humic acids. Geoderma. 17, 239-252.

Orlov D. S. and Sadovnikova L. K. (1975) Content and distribution of carbohydrate in the major soil groups of the USSR. Sortet Soil Sai. 7, 440-449.

RIFFLDI R. and SCHNITZER M. (1973) Effects of $6 \mathrm{~N} \mathrm{HCl}$ hydrolysis on the analytical characteristics and chemical structure of humic acids. Soil Sci. 115, 349-356.

SaIZ-JMENez C. and MARTIN F. (1972) Acidos humicos de origen fungico. I. Espectros infrarrojos. An. Edaf. Agrobiol. 31, 133-140.

SAIZJIMENEZ C. and MARTIN F. (1978) Chemical structure of a fungal humic acid-like pigment. Izlest. Akad. Nauk SSSR, Ser. Biol, 1, 59-65.

SaIZ-Jimenez C. Haider K. and Martin J. P. (1975) Anthraquinones and phenols as intermediates in the formation of dark-colored, humic acid-like piements by Eurotium echinulatum. Soil Sci. Soc. Am. Proc. 37, 649-653.

SCHNitzer M. and Nevroud J. A. (1975) Further investigations on the chemistry of fungal humic acids. Soil Biol. Biochem. 7, 365-371.

SCHNITzER M.. Ortiz de Serra M. I. and lvarson K. (1973) The chemistry of fungal humic acid-like polymers and of soil humic acids. Soil Sri. Soc. Am. Proc. 37, $229-236$

Simmonds P. (1970) Whole microorganisms studied by pyrolysis-gas chromatography-mass spectrometry; signifcance for extraterresirial life detection experiments. Appl. Microbiol. 20, 567-572 